Pesq. Vet. Bras. 30(1):51-56, janeiro 2010

\title{
Meningoencefalite por Listeria monocytogenes em ovinos $^{1}$
}

\author{
Daniel R. Rissi ${ }^{2}$ Glaucia D. Kommers ${ }^{3}$ Clairton Marcolongo-Pereira ${ }^{4}$ \\ Ana L. Schild ${ }^{5}$ e Claudio S.L. Barros ${ }^{3}$
}

\begin{abstract}
Rissi D.R., Kommers G.D., Marcolongo-Pereira C., Schild A.L. \& Barros C.S.L. 2010. [Meningoencephalitis in sheep caused by Listeria monocytogenes.] Meningoencefalite por Listeria monocytogenes em ovinos. Pesquisa Veterinária Brasileira 30(1):51-56. Departamento de Patologia, Universidade Federal de Santa Maria, 97105900 Santa Maria, RS, Brazil. E-mail: claudioslbarros@uol.com.br

Seven cases of neurological disease in sheep caused by Listeria monocytogenes in Rio Grande do Sul and Paraná state, southern Brazil are described. The cases occurred between 2000 and 2007 and 12-24-month-old sheep were affected. Overall morbidity and lethality rates were $3.15 \%$ and $100 \%$, respectively. Cases occurred in the summer and early spring. When this information was available, affected sheep had not been fed with silage. In three farms there were close contact among affected sheep and other species. Clinical signs were characterized by recumbency (7/7), head tilt (4/7), incoordination (3/7), depression (3/7), circling (2/7), unilateral blindness, wasting, fever, midriasis, paddling, opisthotonus, hind or hind and fore limb paralysis, drooling, and muscle tremors (1/7 each). Clinical evolution varied from 12 hours to three days. Histological findings consisted of predominantly unilateral, microabscedative encephalitis with variable degrees of gliosis and degenerative lesions characterized by axonal spheroids and infiltration by Gitter cells. These lesions were observed extending from medulla oblongata to mesencephalon. Listeria monocytogenes antigen was showed by imunohistochemistry in routinely processed sections of brainstem from all seven affected sheep. The diagnostic was based on epidemiological, clinical, and pathological findings and confirmed by immunohistochemistry (IHQ) using polyclonal anti-L. monocytogenes antibody.
\end{abstract}

INDEX TERMS: Listeria sp., Listeria monocytogenes, listeriosis, diseases of sheep, immunohistochemistry, neuropathology.

RESUMO.- São descritos sete casos de doença neurológica em ovinos por Listeria monocytogenes no Rio Grande do Sul e Paraná entre 2000 e 2007. Foram afetados ovinos com idades entre 12-24 meses. Os casos ocorreram no verão e início da primavera e os índices gerais de morbidade e letalidade foram de $3,15 \%$ e $100 \%$, respecti-

\footnotetext{
${ }^{1}$ Recebido em 21 de julho de 2009.

Aceito para publicação em 24 de agosto de 2009.

Parte da tese de doutorado do primeiro autor (bolsista do CNPq).

2 Programa de Pós-Graduação em Medicina Veterinária, área de concentração em Patologia Veterinária, Centro de Ciências Rurais, Universidade Federal de Santa Maria (UFSM), Santa Maria, RS, Brasil.

${ }^{3}$ Departamento de Patologia, UFSM, Santa Maria, RS 97105-900. *Autor para correspondência: claudioslbarros@uol.com.br

${ }^{4}$ Programa de Pós-Graduação em Veterinária, Laboratório Regional de Diagnóstico, Faculdade de Veterinária, Universidade Federal de Pelotas (UFPel), Pelotas, RS 96010-900, Brasil.

${ }^{5}$ Laboratório Regional de Diagnóstico, Faculdade de Veterinária, UFPel, Pelotas, RS.
}

vamente. Quando essa informação estava disponível, nenhum dos ovinos afetados era alimentado com silagem. Em três propriedades havia contato próximo dos ovinos afetados com outras espécies. A evolução do quadro clínico foi de 12 horas a três dias e os sinais clínicos foram caracterizados por decúbito (7/7), desvio da cabeça (4/ 7), incoordenação (3/7), depressão (3/7), andar em círculos $(2 / 7)$, cegueira unilateral, emagrecimento progressivo, febre, midríase, movimentos de pedalagem, nistagmo lateral, opistótono, paralisia flácida dos membros pélvicos ou dos quatro membros, salivação excessiva e tremores (1/7 cada). Histologicamente observou-se encefalite com microabscessos, predominantemente unilateral com variáveis graus de gliose e alterações degenerativas como esferóides axonais e infiltração de células Gitter. As lesões se estendiam desde a medula oblonga até o mesencéfalo. Antígenos de Listeria monocytogenes foram detectados por imuno-histoquímica em seções de tronco encefálico de to- 
dos os ovinos afetados. O diagnóstico foi realizado com base nos achados epidemiológicos e clinico-patológicos, e confirmado pela imuno-histoquímica (IHQ) utilizando anticorpo policlonal anti-L. monocytogenes.

TERMOS DE INDEXAÇÃO: Listeria sp., Listeria monocytogenes, listeriose, doenças de ovinos, imuno-histoquímica, neuropatologia.

\section{INTRODUÇÃO}

A listeriose é uma doença infecciosa causada pelas bactérias Gram-positivas do gênero Listeria (George 2002, Schild 2007). A doença afeta várias espécies animais e seres humanos e pode induzir doença septicêmica, com formação de abscessos em vários órgãos, abortos ou doença neurológica caracterizada por meningoencefalite e formação de microabscessos no tronco encefálico (George 2002). Em um surto de listeriose normalmente se observa somente uma dessas três formas clínicas. Doença neurológica em ruminantes usualmente é causada por Listeria monocytogenes. Essa doença apresenta baixos índices de morbidade e alta letalidade e nesses casos a infecção geralmente é associada à alimentação com silagem ou contato com fezes ou leite de animais portadores (Vandegraaff et al. 1981, Wilesmith \& Gitter 1986, George 2002, Rissi et al. 2006, Schild 2007). A forma neurológica de listeriose em ruminantes no Brasil já foi descrita em bovinos (Sanches et al. 2000), caprinos (Rissi et al. 2006, Guedes et al. 2007) e ovinos (Mendes et al. 2005, Ribeiro et al. 2006, Guedes et al. 2007), porém não existem descrições detalhadas da forma neurológica da enfermidade em ovinos.

O objetivo deste trabalho é descrever os achados epidemiológicos, clínicos e patológicos de sete casos de doença neurológica causada por L. monocytogenes em ovinos na região Sul do Brasil.

\section{MATERIAL E MÉTODOS}

Os casos foram selecionados dos arquivos do Laboratório de Patologia Veterinária (LPV) da Universidade Federal de Santa Maria (UFSM) (Ovinos 1-6) e do Laboratório Regional de
Diagnóstico (LRD) da Universidade Federal de Pelotas (UFPel) (Ovino 7). Os dados epidemiológicos dos Ovinos 1-3 foram obtidos junto aos proprietários e veterinários encarregados dos casos e que enviaram o encéfalo para exame. Os dados dos Ovinos 4-7 foram obtidos junto aos veterinários na ocasião do recebimento do cadáver para necropsia. Os Ovinos 1-3 eram provenientes do Paraná e os Ovinos 4-7 do Rio Grande do Sul. Os encéfalos foram fixados em formol a 10\%. Após a avaliação macroscópica por seções sagitais de $1 \mathrm{~cm}$ foram selecionados os cortes para exame histopatológico (Barros \& Marques 2003). O material foi processado rotineiramente para histologia e corado pela hematoxilina-eosina (HE). Seções selecionadas de bulbo, ponte ou mesencéfalo de todos os casos foram submetidas ao teste de IHQ utilizando anticorpo primário policlonal anti-antígeno celular (O) de Listeria monocytogenes na diluição de 1:1000.

\section{RESULTADOS}

\section{Epidemiologia e sinais clínicos}

Os dados epidemiológicos dos sete ovinos afetados por meningoencefalite por $L$. monocytogenes estão no Quadro 1. Os sinais clínicos eram caracterizados, em ordem decrescente de freqüência, por decúbito (7/7), desvio lateral da cabeça (4/7) (Fig.1), incoordenação (3/7),

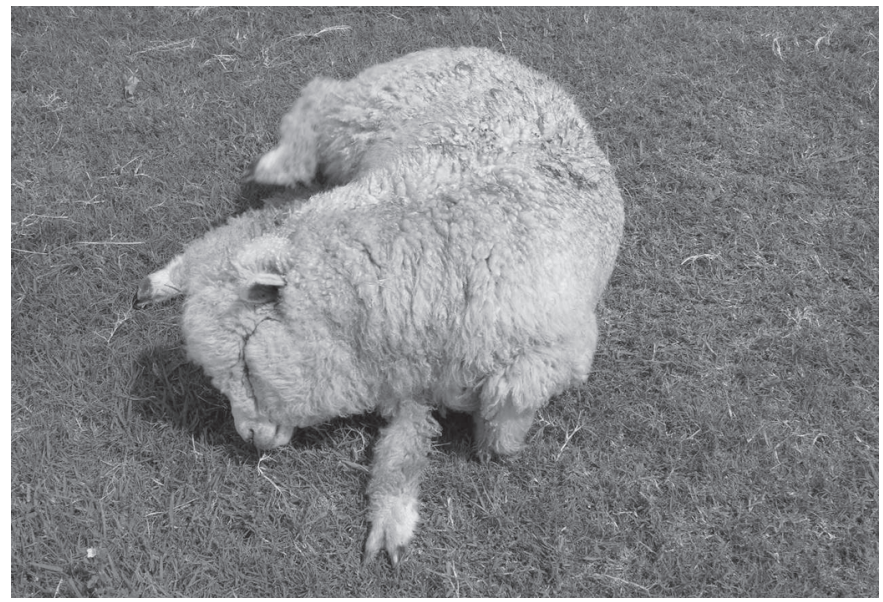

Fig,1. Ovino 7 apresentando decúbito e marcado desvio lateral da cabeça.

Quadro 1. Dados epidemiológicos de sete ovinos afetados por meningoencefalite por Listeria monocytogenes no Sul do Brasil

\begin{tabular}{|c|c|c|c|c|c|c|c|c|c|}
\hline$O v^{a} / P^{b}$ & Época & Idade $^{c}$ & Sexo & Raça & Alimentação & $\begin{array}{l}\text { Contato com } \\
\text { outros animais }\end{array}$ & $\begin{array}{l}\text { Ovinos } \\
\text { sob risco }\end{array}$ & $\begin{array}{l}\text { Ovinos } \\
\text { afetados }\end{array}$ & $\begin{array}{l}\text { Ovinos } \\
\text { mortos }\end{array}$ \\
\hline $1 / A$ & Jan. 2002 & $\mathrm{ni}^{\mathrm{d}}$ & $\mathrm{F}^{\mathrm{e}}$ & Suffolk & $\begin{array}{l}\text { Pastagem nativa } \\
\text { e ração no cocho }\end{array}$ & Não & 70 & 2 & 2 \\
\hline $2 / \mathrm{B}$ & Dez. 2003 & 12 & $\mathrm{~F}$ & Santa Inês & $\mathrm{ni}$ & ni & 700 & 32 & 32 \\
\hline $3 / B$ & Dez. 2003 & 12 & $\mathrm{~F}$ & Santa Inês & ni & ni & 700 & 32 & 32 \\
\hline $4 / C$ & Dez. 2004 & Adulta & ni & Mista & Pastagem nativa & Não & $\mathrm{ni}$ & $\mathrm{ni}$ & $\mathrm{ni}$ \\
\hline $5 / D$ & Ago. 2007 & Adulta & $\mathrm{F}$ & Mista & $\begin{array}{l}\text { Pastagem de azevém } \\
\text { e milho e farelo de } \\
\text { soja no cocho }\end{array}$ & $\begin{array}{l}\text { Galinhas e patos } \\
\text { com livre acesso } \\
\text { aos cochos }\end{array}$ & 300 & 1 & 1 \\
\hline $6 / E$ & Out. 2007 & 24 & $\mathrm{~F}$ & Mista & Pastagem nativa & $\begin{array}{l}\text { Bovinos, porcos } \\
\text { e galinhas }\end{array}$ & 28 & 4 & 4 \\
\hline $7 / F$ & Mar. 2006 & Adulta & $\mathrm{F}$ & Mista & $\begin{array}{l}\text { Pastagem nativa e } \\
\text { resteva de arroz }\end{array}$ & Bovinos & 170 & 1 & 1 \\
\hline
\end{tabular}


depressão (3/7), andar em círculos (2/7), cegueira unilateral (1/7), emagrecimento (1/7), febre (1/7), midríase (1/ 7), movimentos de pedalagem (1/7), nistagmo lateral (1/ 7), opistótono (1/7), paralisia flácida dos membros pélvi$\cos (1 / 7)$ ou dos quatro membros (1/7), salivação excessiva (1/7) e tremores (1/7). A evolução clínica foi de 12 horas a três dias. Os Ovinos 1 e 6 foram tratados com antibióticos no início do aparecimento dos sinais clínicos, mas não apresentaram melhora. Os casos ocorreram em dois municípios do Paraná (Ovinos 1-3) e três municípios do Rio Grande do Sul (Ovinos 4-7).

\section{Patologia}

Os Ovinos 1-3, 5 e 6 não apresentaram alterações macroscópicas. Uma área cavitária, focal, escura e mole (malacia) foi observada na região do núcleo vermelho direito (mesencéfalo na altura do colículo rostral) do Ovino
7. Essa lesão se estendia até a altura do colículo caudal. No Ovino 4 foram observadas áreas multifocais vermeIho-escuras e firmes nas porções apicais do lobo pulmonar cranial direito (pneumonia aspirativa). Histologicamente, todos os ovinos apresentavam meningoencefalite microabscedativa localizada no tronco encefálico e que se estendia desde o bulbo até o mesencéfalo. As lesões eram predominantemente unilaterais e consistiam de manguitos perivasculares multifocais linfo-histioplasmocitários que variavam de moderados a acentuados (Fig.2). Esses manguitos eram associados a múltiplos agregados de neutrófilos aleatoriamente distribuídos no neurópilo (microabscessos) (Fig.3). Nessas áreas havia intensa reação glial, rarefação do neurópilo (edema) e esferóides axonais em meio às lesões (Fig.4). Ocasionalmente havia infiltração focal de células Gitter (malacia) (Fig.5). Todas as seções de tronco encefálico dos ovinos afeta-
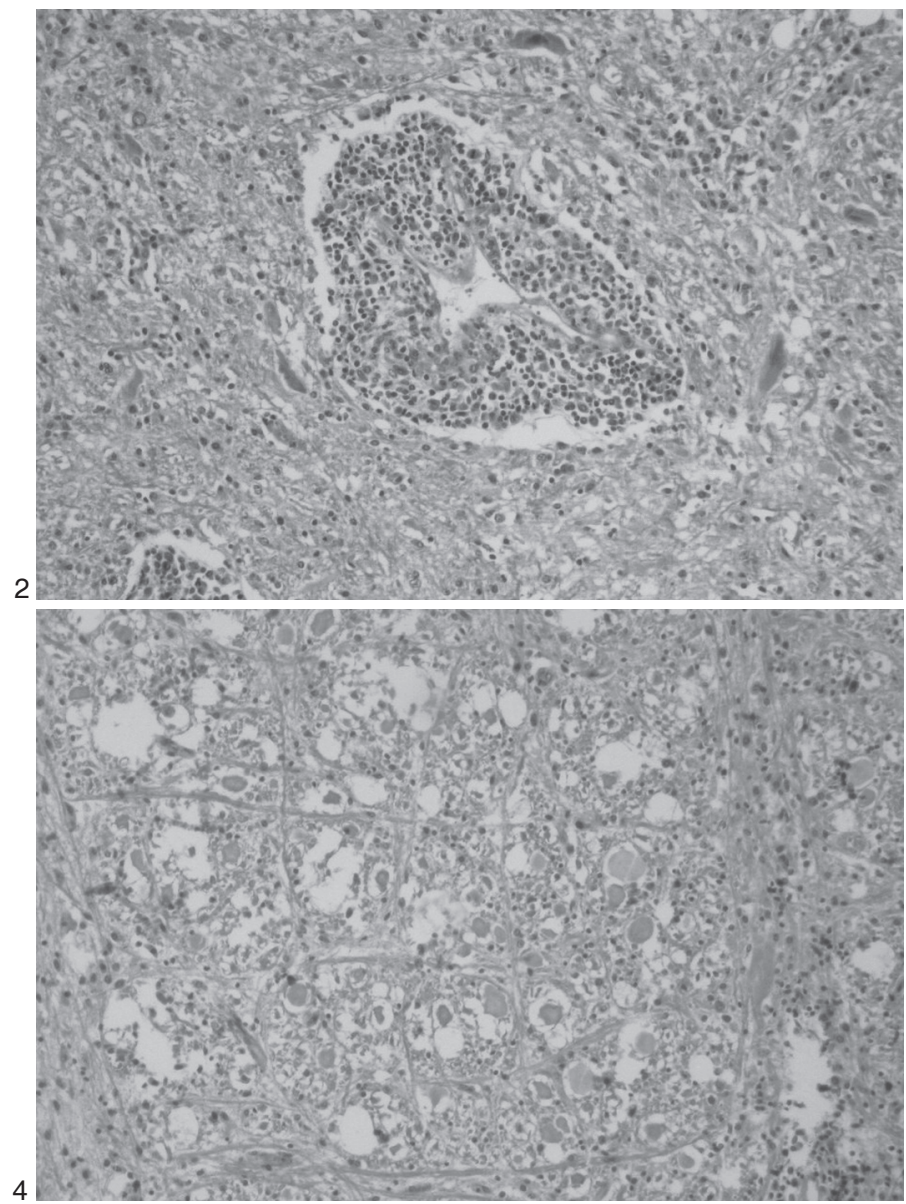

Fig.2. Infiltrado inflamatório perivascular linfo-histioplasmocitário no tronco encefálico (ponte) do Ovino 6 afetado por meningoencefalite por Listeria monocytogenes. Há gliose acentuada no neurópilo adjacente. HE, obj.20x.

Fig.4. Bulbo do Ovino 5 afetado por meningoencefalite por Listeria monocytogenes. Numerosos axônios tumefeitos (esferóides) em meio ao neurópilo rarefeito (edema) são observados na formação reticular. HE, obj.20x.
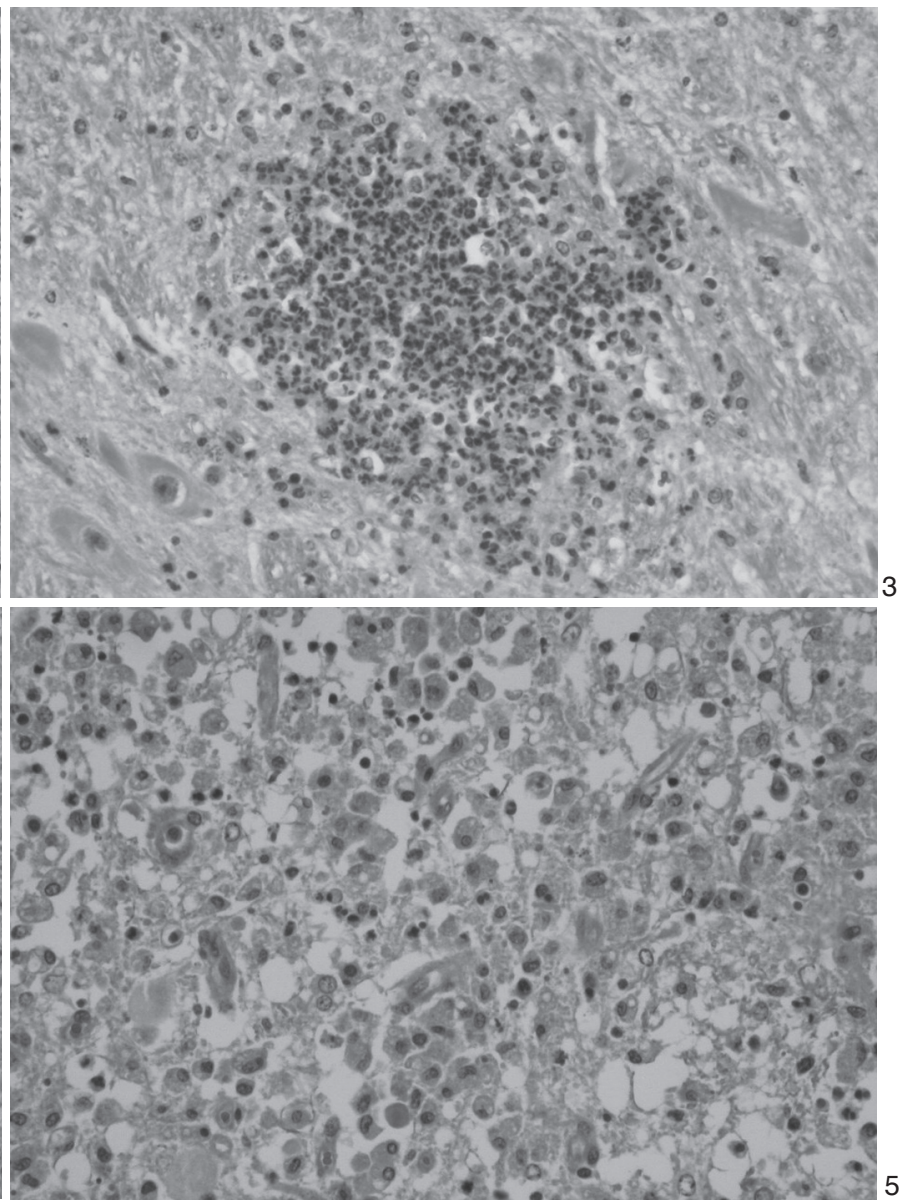

Fig.3. Acúmulo focal de neutrófilos (microabscesso) no bulbo do Ovino 6 afetado por meningoencefalite por Listeria monocytogenes. Essa lesão foi um achado constante nos sete ovinos afetados. HE, obj.40x.

Fig.5. Bulbo do Ovino 6 afetado por meningoencefalite por Listeria monocytogenes. Numerosos macrófagos com citoplasma tumefeito e espumoso (células Gitter) são observados preenchendo um foco de malacia. Há tumefação do endotélio vascular. HE, obj.40x. 


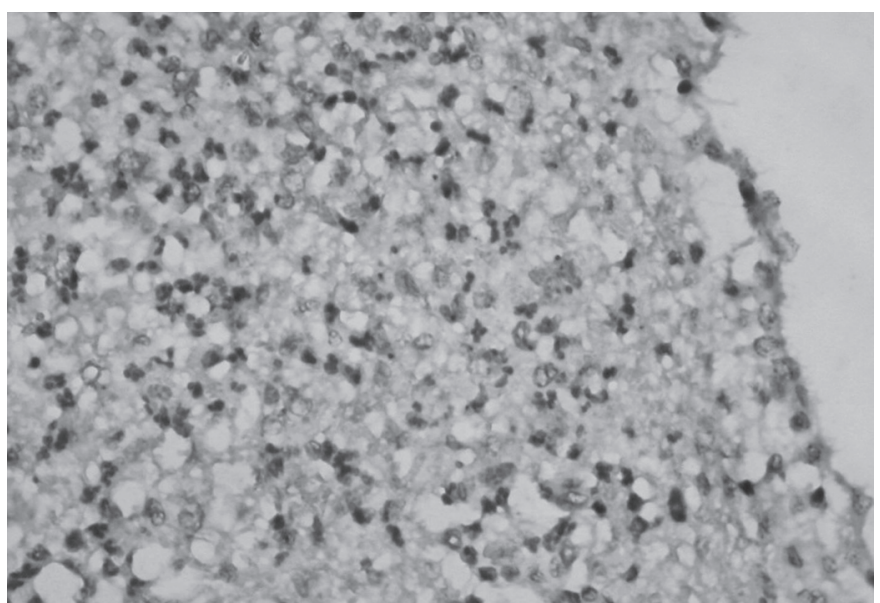

Fig.6. Imuno-histoquímica em seção da ponte do Ovino 6. Observam-se múltiplos pontos vermelhos (setas) marcados no interior de células inflamatórias de um microabscesso. Esses pontos correspondem a antígenos bacterianos marcados positivamente pelo anticorpo anti-Listeria monocytogenes. Imuno-histoquímica, método da estreptavidina-biotinafosfatase alcalina, obj.40x.

dos foram positivas no teste de IHQ para L. monocytogenes (Fig. 6).

\section{DISCUSSÃO}

O diagnóstico de listeriose foi realizado com base nos achados clínicos, epidemiológicos e histológicos e confirmado pela detecção do agente pela técnica de IHQ. Os casos deste estudo ocorreram no verão e início da primavera e em cinco ocasiões onde essa informação estava disponível, os rebanhos não eram alimentados com silagem. Essas características são diferentes do que é relatado em outros países, onde a ocorrência da doença é mais alta nos meses de inverno (Vandegraaff et al. 1981, Wardrope \& Macleod 1983, Barlow \& McGorum 1985, Wilesmith \& Gitter 1986) e normalmente é associada à alimentação com silagem de má qualidade (Barlow \& McGorum 1985, Wilesmith \& Gitter 1986). O aumento dos casos de listeriose nesses períodos é atribuído às condições climáticas desfavoráveis e à conseqüente queda de qualidade da silagem (Wilesmith \& Gitter 1986). O estresse provocado pelo frio intenso, associado aos altos índices pluviométricos, agrupamento do rebanho e pastagem de má qualidade são fatores que também contribuem para o desenvolvimento da doença nesses locais (Vandegraaff et al. 1981, Wilesmith \& Gitter 1986). No Brasil a situação parece se inverter e a maioria dos casos de meningoencefalite por $L$. monocytogenes em ruminantes ocorre nos meses mais quentes do ano e na maioria das vezes não ocorre associada à alimentação com silagem ou ao menos não há comprovação definitiva do envolvimento desse produto na transmissão da doença (Sanches et al. 2000, Rissi et al. 2006, Schild 2007). Meningoencefalite por $L$. monocytogenes não associada à alimentação com silagem ocorre ocasionalmente em outros países (Vandegraaff et al. 1981) e normalmente esses casos são associados à contaminação ambiental (George 2002). L. monocytogenes é habitante do solo ou de matéria vegetal decomposta e pode ser isolada de fezes de vários animais domésticos e selvagens (Low \& Linklater 1985, George 2002) ou de secreção nasal e fezes de ovinos normais (Killinger \& Mansfield 1970). O papel epidemiológico dessas potenciais fontes de infecção parece ser o determinante em casos de meningoencefalite por $L$. monocytogenes em ruminantes no Brasil (Rissi et al. 2006) e provavelmente foi o que ocorreu nos casos deste estudo. A contaminação ambiental (pastagem ou ração) por L. monocytogenes parece ter sido a origem da doença nos Ovinos 1-4 (Propriedades $\mathrm{A}-\mathrm{C}$ ), enquanto que o contato direto com fezes ou outras secreções de galinhas, patos, bovinos e porcos pode ter sido a fonte de infecção dos Ovinos 5-7 (Propriedades $\mathrm{D}-\mathrm{F})$.

A doença ocorreu na forma de surtos (Propriedades $A, B$ e E) ou de casos isolados (Propriedades D e F). Não havia informações epidemiológicas satisfatórias na propriedade C. De um total de 1.268 ovinos sob risco nas seis propriedades, 40 adoeceram e morreram após evolução clínica de 12 horas a três dias. Esses dados geram índices gerais de morbidade, mortalidade e letalidade, respectivamente, de 3,15\%, 3,15\% e 100\%, e são semeIhantes aos descritos em outros surtos de meningoencefalite por L. monocytogenes em ovinos (Vandegraaff et al. 1981, Reuter et al. 1989). A doença é mais comum em ovinos adultos, como foi observado neste estudo, e raramente ocorre em cordeiros (Wardrope \& MacLeod 1983).

A maioria dos sinais clínicos desenvolvidos por animais afetados pela forma neurológica da listeriose está relacionada com a distribuição das lesões no tronco encefálico e, em menor grau, no cerebelo (Constable 2004, Rissi et al. 2006). Em todos os casos deste estudo foram observadas lesões histológicas inflamatórias e degenerativas que se estendiam desde a medula cervical até 0 mesencéfalo e a maioria dos sinais clínicos (incoordenação, andar em círculos, torneio, desvio da cabeça, salivação excessiva, depressão, opistótono, midríase e tremores) pôde ser associada com essa localização. A paralisia flácida dos membros desenvolvida pelos Ovino 1 e 7 poderia ser explicada por uma lesão medular no entanto, somente o encéfalo foi examinado, o que impossibilitou a comprovação dessa possibilidade. A condição geral dos animais afetados por listeriose rapidamente deteriora e os força a entrar em decúbito alguns dias após o início dos sinais clínicos, como ocorreu nos casos deste estudo.

Os achados histopatológicos nos sete ovinos deste estudo são semelhantes aos descritos em casos de listeriose em ovinos e em outros ruminantes (George 2002, Mendes et al. 2005, Rissi et al. 2006). A localização das lesões no tronco encefálico está relacionada à porta de entrada da infecção, normalmente em locais próximos às terminações de nervos cranianos, principalmente facial e trigêmeo (Borman et al. 1960). Essas portas de entrada 
incluem lesões na mucosa oral, decorrentes de ingestão de alimentos fibrosos e erupções dentárias, ou lesões na mucosa nasal e conjuntival (Otter \& Blakemore 1989, Wesley 1999), porém nenhuma dessas lesões foi observada nos ovinos deste estudo.

Seções de tronco encefálico de todos os ovinos afetados foram positivas na imuno-histoquímica. Apesar de existirem suspeitas de reação cruzada entre espécies de Listeria (Rissi et al. 2006) nesse teste, o diagnóstico de meningoencefalite por $L$. monocytogenes nestes casos é bastante seguro, pois é descrito que somente essa espécie está associada com doença neurológica em ruminantes (Schneider 1994, Low \& Donachie 1997). Marcação positiva foi observada em todos os casos e antígenos bacterianos foram detectados no citoplasma de neutrófilos e macrófagos que compunham os focos de microabscessos no tronco encefálico. Marcação positiva não foi observada em células inflamatórias dos manguitos perivasculares ou em neurônios como descrito em outros casos (Marco et al. 1988, Rissi et al. 2006). A técnica de IHQ tem sido usada com eficiência no diagnóstico de listeriose (Peixoto 1986, Marco et al. 1988, Johnson et al. 1995, Weinstock et al. 1995, Ramos-Vara \& Beissenherz 2000, Campero et al. 2002, Loeb 2004) por apresentar maior rapidez e sensibilidade quando comparada à cultura bacteriana e à técnica de coloração de Gram, respectivamente (Marco et al. 1988, Johnson et al. 1995, Rissi et al. 2006). Alguns autores (Johnson et al. 1995) relatam dificuldades no isolamento bacteriano de amostras provenientes de ruminantes acometidos por doeça neurológica causada por $L$. monocytogenes, mesmo quando remetidas apropriadamente. Uma explicação para esse problema poderia se basear no fato de que alguns casos da doença, particularmente em bovinos, podem estar associados a pouca ou nenhuma quantidade de bactérias intralesionais (Johnson et al. 1995). Além disso, o isolamento de Listeria spp. exige condições especiais de cultura (Wardrope \& MacLeod 1983) e requer aproximadamente um mês para que o resultado possa ser confirmado (MacLeod \& Wells 1986). Em relação à coloração de Gram, normalmente se observa menor quantidade de bactérias quando comparada à técnica de $\mathrm{IHQ}$ (Marco et al. 1988) e, em alguns casos, nem mesmo se observa marcação do agente nas seções examinadas (Barlow \& McGorum 1985). Diferentes padrões de positividade frente às técnicas de Brown \& Brenn (BB) e de IHQ foram observados em um surto de doença neurológica por $L$. monocytogenes em caprinos (Rissi et al. 2006). Nesses casos a técnica de BB permitiu a detecção de grande quantidade de bactérias em um caprino com evolução clínica de 10 dias (e que histologicamente apresentava microabscessos), pequena quantidade em um caprino com evolução clínica de cinco dias (e que apresentava múltiplos focos de malacia) e nenhuma bactéria em um caprino com evolução de 30 dias (com lesões granulomatosas). Após a realização de $\mathrm{IHQ}$, antígenos bacterianos foram observados em grande quantidade no primeiro caprino, mode- rada quantidade no segundo e pequena quantidade no terceiro caprino. Esses achados indicam que há uma possível influência da evolução clínica e da natureza das lesões na quantidade de bactérias intralesionais em um surto de meningoencefalite por $L$. monocytogenes em ruminantes e que isso pode interferir no diagnóstico dependendo da técnica utilizada.

A quantidade de antígenos bacterianos marcados pela técnica de $\mathrm{IHQ}$ variou substancialmente entre os encéfalos dos ovinos deste estudo e os encéfalos de caprinos afetados pela forma neurológica de listeriose descritos em outra ocasião (Rissi et al. 2006). Nesse trabalho, o caprino que apresentava lesões clássicas de listeriose, semelhantes às desenvolvidas pelos ovinos do presente relato, apresentava grande número de antígenos bacterianos intralesionais. Por outro lado, a técnica de IHQ marcou poucos ou raros antígenos intralesionais no encéfalo destes ovinos. As defesas do hospedeiro contra patógenos intraceculares se baseiam amplamente na capacidade de produção de óxido nítrico pelos macrófagos (Pfister et al. 2002) e talvez possam explicar essa diferença de marcação antigênica no encéfalo de ovinos e caprinos. A óxido nítrico-sintase, enzima responsável pela formação de óxido nítrico pelos macrófagos, apresenta diferenças de expressão entre bovinos, ovinos e caprinos afetados por meningoencefalite por L. monocytogenes. Os níveis de expressão dessa enzima são altos em bovinos, intermediários em ovinos e baixos em caprinos e esses índices são inversamente proporcionais à quantidade de bactérias intralesionais em casos de doença neurológica por $L$. monocytogenes em ruminantes (Pfister et al. 2002).

O tratamento intravenoso com antibióticos é pouco eficaz em ovinos, principalmente se os animais já estiverem em uma fase adiantada da doença (Schild 2007). Em casos de meningoencefalite por $L$. monocytogenes em caprinos, uma cabra foi tratada e apresentou pequena melhora clínica seguida de recidiva dos sinais clínicos e morte após 30 dias do tratamento, indicando, como foi o caso neste estudo, que mesmo tratados no início da doença, animais afetados pela doença dificilmente apresentam melhora clínica após tratamento com antibióticos (Rissi et al. 2006).

O diagnóstico de listeriose em todos os casos foi realizado com base nos achados epidemiológicos e clinicopatológicos, e confirmado pela imuno-histoquímica (IHQ) utilizando anticorpo policlonal anti-L. monocytogenes.

\section{REFERÊNCIAS}

Barlow R.M. \& McGorum B. 1985. Ovine listerial encephalitis: analysis, hypotesis and synthesis. Vet. Rec. 116:233-236.

Barros C.S.L. \& Marques G.H.F. 2003. Procedimentos para o diagnóstico das doenças do sistema nervoso central de bovinos. Departamento de Defesa Animal, Ministério da Agricultura, Pecuária e Abastecimento (MAPA), Brasília. 50p. (Disponível na internet: http:// www.agricultura.gov.br)

Borman G., Olson C. \& Segre D. 1960. The trigeminal and facial nerves as pathways for infection of sheep with Listeria monocytogenes. Am. J. Vet. Res. 21:993-1000. 
Campero C.M., Odeón A.C., Cipolla A.L., Moore D.P., Poso M.A. \& Odriozola E. 2002. Demonstration of Listeria monocytogenes by immunohistochemistry in formalin-fixed brain tissues from natural cases of ovine and bovine encephalitis. J. Vet. Med. B 49:379-383.

Constable P.D. 2004. Clinical examination of the ruminant nervous system. Vet. Clin. Food. Anim. 20:185-214.

George L.W. 2002. Listeriosis, p.946-949. In: Smith B.P. (Ed.), Large Animal Internal Medicine. $3^{\text {rd }}$ ed. Mosby, St Louis. 1735p.

Guedes K.M.R., Riet-Correa F., Dantas A.F.M., Simões S.V.D., Neto E.G.M., Nobre V.M.T. \& Medeiros R.M.T. 2007. Doenças do sistema nervoso central em caprinos e ovinos no semiárido. Pesq. Vet. Bras. 27:29-38.

Johnson G.C., Fales W.H., Maddox C.W. \& Ramos-Vara J.A. 1995. Evaluation of laboratory tests for confirming the diagnosis of encephalitic listeriosis in ruminants. J. Vet. Diagn. Invest. 7:223-228.

Killinger A.H. \& Mansfield M.E. 1970. Epizootiology of listeric infection in sheep. J. Am. Vet. Med. Assoc. 157:1318-1324.

Loeb E. 2004. Encephalitic listeriosis in ruminants: Immunohistochemistry as a diagnostic tool. J. Vet. Med. A 51:453-455.

Low J.C. \& Linklater K. 1985. Listeriosis in sheep. In Practice March:6667.

Low J.C. \& Donachie W. 1997. A review of Listeria monocytogenes and listeriosis. Vet. J. 153:9-29.

Marco A., Ramos J.A., Dominguez L., Domingo M. \& Gonzalez L. 1988. Immunocytochemical detection of Listeria monocytogenes in tissue with the peroxidase-antiperoxidase technique. Vet. Pathol. 25:385-387.

McLeod N.S. \& Wells R. 1986. Isolation of L. monocytogenes from ovine brain. Vet. Rec. $118: 309-310$.

Mendes T.C., Ferreira J.L.M., Azambuja V.B., Ladeira S.L., Tortelli F.P., Pereira G.M. \& Raffi M.B. 2005. Listeriose em ovinos. Arq. Bras. Med. Vet. Zootec. 57(Supl.1):36.

Otter A. \& Blakemore W.F. 1989. Observation on the neural transport of Listeria monocytogenes in a mouse model. Neuropathol. Appl. Neurol. 15:590.

Peixoto P.V. 1986. Vergleichende histopathologische und immunhistologische Untersuchungen zur Diagnose spontaner Listeriose bei Tieren: Eine retrospektive Studie mit der Peroxidase-Antiperoxidase(PAP)-Technik an formalinfixierten Paraffinschnitten. Dissertation, Justus-Liebig-Universität Giessen. 109p.
Pfister H., Remer K.A., Brcic M., Fatzer R., Christen S., Leib L. \& Jungi T.W. 2002. Inducible nitric oxide synthase and nitrotyrosine in listeric encephalitis: A cross-species study in ruminants. Vet. Pathol. 39:190199.

Ramos-Vara J.A. \& Beissenherz M.E. 2000. Optimization of immunohistochemical methods using two different antigen retrieval methods on formalin-fixed, paraffin-embedded tissues: Experience with 63 markers. J. Vet. Diagn. Invest. 12:307-311.

Reuter R., Bowden M. \& Palmer M. 1989. Ovine listeriosis in south coastal Western Australia. Aust. Vet. J. 66:223-224.

Ribeiro L.A.O., Rodrigues N.C., Fallavena L.C.B., Oliveira S.J. \& Brito M.A. 2006. Listeriose em rebanho de ovinos leiteiros na região serrana do Rio Grande do Sul: relato de caso. Arq. Bras. Med. Vet. Zootec. 58:316-319.

Rissi D.R., Rech R.R., Barros R.R., Kommers G.D., Langohr I.M., Pierezan F. \& Barros C.S.L. 2006. Forma nervosa de listeriose em caprinos. Pesq. Vet. Bras. 26(1):14-20.

Sanches A.W.D., Langohr I.M., Stigger A.L. \& Barros C.S.L. 2000. Doenças do sistema nervoso central em bovinos no sul do Brasil. Pesq. Vet. Bras. 20:113-118.

Schild A.L. 2007. Listeriose, p.352-357. In: Riet-Correa F., Schild A.L., Lemos R.A.A. \& Borges J.R. (Eds), Doenças de Ruminantes e Eqüídeos. Vol.1. Equali, Campo Grande, MS. 722p.

Schneider D.J. 1994. Listeriosis, p.1374-1377. In: Coetzer J.A.W., Thomson G.R. \& Tustin R.C. (Eds), Infectious Diseases of Livestock with Special Reference to Southern Africa. Vol.2. Oxford University Press, Cape Town. 1605p.

Vandegraaff R., Borland N.A. \& Browning J.W. 1981. An outbreak of listerial meningoencephalitis in sheep. Aust. Vet. J. 57:94-96.

Wardrope D.D. \& McLeod N.S. 1983. Outbreak of Listeria meningoencephalitis in young lambs. Vet. Rec. 113:213:214.

Weinstock D., Horton S.B. \& Rowland P.H. 1995. Rapid diagnosis of Listeria monocytogenes by immunohistochemistry in formalin-fixed brain tissue. Vet. Pathol. 32: 193-195

Wesley I.V. 1999. Listeriosis in animals, p.39-73. In: Ryser E.T. \& Marth E.H. (Eds), Listeria, Listeriosis, and Food Safety. $2^{\text {nd }}$ ed. Marcel Dekker, New York. 738p.

Wilesmith J.W. \& Gitter M. 1986. Epidemiology of ovine listeriosis in Great Britain. Vet. Rec. 119:467-470. 